\title{
Anesthesia management of Jansen's metaphyseal dysplasia
}

\author{
Ugur Goktas ${ }^{1, *}$, Murat Tekin ${ }^{2}$, Ismail Kati $^{3}$ \\ ${ }^{1}$ Department of Anesthesiology, Medical Faculty, Yuгuncu Yil University, Van, Turkey \\ ${ }^{2}$ Department of Anesthesiology, Medical Faculty, Kocaeli University, Kocaeli, Turkey \\ ${ }^{3}$ Department of Anesthesiology, Medical Faculty, Gazi University, Ankara, Turkey
}

\begin{abstract}
Metaphyseal chondrodysplasia is a rare autosomal dominant disorder characterized by accumulation of cartilage in specifically metaphysis of tubular bones. Hyperkalemia and hypophosphatemia were seen most of these patients. In this article we intended to draw attention to some issues releated with anesthesia hereby that a 9 year-old patient with Jansen's metaphyseal dysplasia.
\end{abstract}

Key Words: general anesthesia, congenital anomalies, drugs

\section{Introduction}

Metaphyseal chondrodysplasia is a very rare autosomal dominant disorder affected of enchondral ossification in especially metaphysis (1). Firstly described in 1934 by Murk Jansen as various severity and degrees (2), and metaphyseal chondrodysplasia was classified in 1957 by Weil. Jansen type, which is the one of the most serious and rare. Hyperkalemia and hypophosphatemia were seen half of these patients $(3,4)$. In this article we intended to draw attention to some issues related with anesthesia management that a 9 year-old patient a with Jansen's metaphyseal dysplasia which to be a disorder very rare and hardest diagnosing.

\section{Case report}

Nine-year-old male patient was diagnosed with Jansen type metaphyseal dysplasia. Patient that planned operation with keratitis due to lagophthalmos has been preoperatively examined for the anesthesia and multiple deformities in upper and lower extremities were found. Clubbing and multiple swelling of joints were found which does not restrict joint movement. Other clinical examination was normal. Laboratory values were found normal (Table 1). We did not apply premedication. Induction was made with fentanil (2 $\mu \mathrm{g} / \mathrm{kg})$, etomidate $(0.3 \mathrm{mg} / \mathrm{kg})$ but neuromuscular agent did not used. Laryngeal mask (LMA) (size 2) has been used for to control the airway safety. Sevoflurane (1-2\%), oxygen (40\%) and nitrousoxyde
$(60 \%)$ were used for the anesthesia management. Operation duration was $50 \mathrm{~min}$. LMA was removed postoperatively without any problem. Control serum potassium and phosphor levels peroperatively and postoperatively were found normal (Table 1). After the recovery patient was sent to the ward without any problem.

\section{Discussion}

Jansen type metaphyseal dysplasia is a very rare and serious disorder in the enchondral ossification diseases. Affecting the metaphyses such as achondroplasia, various types of rickets, hypophosphatasia and multiple enchondromatosis were excluded in differential diagnosis of Jansen type metaphyseal dysplasia. Achondroplasia can be described as soon after birth anomalies and typical facial appearance. In metaphyseal disorders; joint abnormalities can be noticed after the patient walking especially age of 4 or 5 . In multiple enchondromatosis radiografically growth plate has not been affected we do not see abnormalities but in metaphyseal dysplasia having enchondral ossification in growth plate came across abnormal appearance. Various types of rickets and hypophosphatasia can be differentiated by the biochemical findings (5). Electrolyte abnormalities are common in Jansen type metaphyseal dysplasia cases. These abnormalities include hyperkalemia and hypophosphatemia that carries risk especially in terms of anesthesia. Micrognathia can be seen in Jansen type metaphyseal dysplasia (6) that may 
Table 1. The patient's laboratory values

\begin{tabular}{lccc}
\hline & Preoperative & Intraoperative & Postoperative \\
\hline $\mathrm{K}(\mathrm{mmol} / \mathrm{L})(3.5-5.1)$ & 4.5 & 4.3 & 4.4 \\
$\mathrm{P}(\mathrm{mmol} / \mathrm{L})(1.0-1.5)$ & 1.45 & 1.46 & 1.45 \\
$\mathrm{Cl}(\mathrm{mmol} / \mathrm{L})(96-106)$ & 102 & 103 & 103 \\
$\mathrm{Na}(\mathrm{mmol} / \mathrm{L})(135-145)$ & 136 & 138 & 138 \\
$\mathrm{Cr}(\mu \mathrm{mol} / \mathrm{L})(50-110)$ & 21.2 & 22.1 & 22.8 \\
$\mathrm{U}(\mathrm{mmol} / \mathrm{L})(2.9-8.9)$ & 6.07 & 6.02 & 6.03 \\
$\mathrm{Glu}(\mathrm{mmol} / \mathrm{L})(3.9-6.1)$ & 5.05 & 5.12 & 5.47 \\
$\mathrm{INR}(\%)(0.8-1.2)$ & 1.15 & 1.22 & 1.19 \\
$\mathrm{PT}(\mathrm{sec})(9-12)$ & 14.7 & 14.9 & 14.8 \\
$\mathrm{PTT}(\mathrm{sec})(22-37)$ & 36.6 & 35.9 & 34.7 \\
\hline
\end{tabular}

causes endotracheal intubation problems. But there was no significant micrognathia in our case and we used laryngeal mask without any problem.

Hyperkalemia may have specific symptoms on the nerve, muscle and gastrointestinal tract but most typical symptom is on the cardiovascular system. Hyperkalemia effects become more serious by some anesthetic agents such as succinylcholine that may causes hyperkalemia and halothane that may causes arrhythmia. Also respiratory problems especially postoperative period has been reported in hypophosphatemic patients.

We wanted to draw attention to these issues; micrognathia and joint abnormalities should be examined preoperatively that can cause endotracheal intubation problems, hyperkalemia and hypophosphatemia should be corrected preoperatively for a properly functioning of cardiac and respiratory systems.

Acknowledgments: This study did not receive financial support.

\section{References}

1. Charrow J, Poznanski AK. The Jansen type of metaphyseal chondrodysplasia: Confirmation of dominant inheritance and review of radiographic manifestations in the newborn and adult. Am J Med Genet 1984; 18: 321-327.

2. Jansen M. 1934 Übber atypische Chondrodystrophie (Achondroplasie) und über eine noch nicht beschriebene angeborene Wachstumsstarung des Knochensystems: Metaphysare Dysostosis. Z Orthop Chir 1934; 61: 253-286.

3. Gordon SL, Varano LA, Alandete A, Maisels MJ. Jansen's metaphyseal dysostosis. Pediatrics 1976; 58: 556-560.

4. Parfitt AM, Schipani E, Rao DS, et al. Hypercalcemia due to constitutive activity of parathyroid hormone (PTH)/PTH-related peptide receptor: Compari-son with primary hyperparathyroidism. J Clin Endocrinol Metabl 1996; 81: 3584-3588.

5. Kikuchi S, Hasue M, Watanabe M, Hasebe K. Metaphysial Dysostosis (Jansen Type). The Journal of Bone and Joint Surgery 1976; 58: 102-106.

6. Kruse K, Schutz C. Calcium metabolism in the Jansen type of metaphyseal dysplasia. Eur J Pediatr 1993; 152: 912-915. 